\title{
Prognostic Value of Red Blood Cell Distribution Width in Non-small Cell Lung Cancer Treated With Anti-programmed Cell Death-1 Antibody
}

\author{
TATSUNORI KIRIU, MASATSUGU YAMAMOTO, TATSUYA NAGANO, \\ KIYOKO KOYAMA, MASAHIRO KATSURADA, DAISUKE TAMURA, KYOSUKE NAKATA, \\ MOTOKO TACHIHARA, KAZUYUKI KOBAYASHI and YOSHIHIRO NISHIMURA \\ Division of Respiratory Medicine, Department of Internal Medicine, \\ Kobe University Graduate School of Medicine, Kobe, Japan
}

\begin{abstract}
Background/Aim: Red cell distribution width $(R D W)$ has been reported to reflect the inflammation and nutrition status and predict prognosis of non-small cell lung cancer (NSCLC) patients treated with anti-programmed cell death-1 (PD-1) antibody. The aim of this study was to analyze the correlation between $R D W$ and prognosis of NSCLC patients. Patients and Methods: We collected retrospective data on consecutive NSCLC patients treated with anti-PD-1 antibody from December 2015 to April 2018 at the Kobe University Hospital, Japan. Results: Forty-seven patients were treated. Patients with $R D W \geq 16 \%$ had a significantly shorter $O S(p=0.010)$ compared to those with $R D W<16 \%$. In multivariate analysis, $R D W \geq 16 \%$ was an independent factor predicting poor prognosis $(p=0.019)$. Conclusion: Pre-treatment $R D W \geq 16 \%$ is an indicator of poor prognosis. $R D W$ is an inexpensive, convenient, and routinely available marker of prognosis.
\end{abstract}

Cancer immunotherapy (CIT) plays an important role in anticancer therapy along with surgery, radiotherapy, chemotherapy, and molecular targeted therapy for metastatic non-small cell lung cancer (NSCLC). The results of phase III trials of immune checkpoint inhibitors (1-4) for previously

This article is freely accessible online.

Correspondence to: Masatsugu Yamamoto, M.D., Ph.D. Assistant Professor of Division of Respiratory Medicine, Department of Internal Medicine, Kobe University Graduate School of Medicine, 7-5-1 Kusunoki-cho, Chuo-ku, Kobe, 650-0017, Japan. Tel: +81 783825660, Fax: +81 783825661, e-mail: myamamot@med.kobeu.ac.jp

Key Words: Red blood cell distribution width, neutrophil-tolymphocyte ratio, non-small cell lung cancer, anti-programmed cell death-1 antibody, prognostic marker. treated NSCLC have been reported. Pembrolizumab, an antiprogrammed cell death-1 (PD-1) antibody, improved overall survival (OS) in patients with a programmed cell deathligand-1 (PD-L1) tumor proportion score (TPS) $\geq 1 \%$, and OS and progression-free survival (PFS) in patients with PD-L1 TPS $\geq 50 \%$ (1). This above-mentioned result suggests that PD-L1 TPS $1-49 \%$ is useful for the prediction of prognosis, but not for predicting efficacy. In contrast, atezolizumab, another anti-PD-L1 antibody, improved OS in previously treated NSCLC patients with or without PD-L1 expression on tumor cells and with or without tumor-infiltrating immune cells (2). CIT involving nivolumab, pembrolizumab, and atezolizumab has led to better survival outcomes than docetaxel monotherapy for previously treated NSCLC (1-4). Therefore, an investigation of factors that predict the prognosis of patients with NSCLC and, more specifically, the treatment effect of CIT is required.

Recently, many studies (5-12) reported on the relationships between various hematological parameters reflecting systemic inflammation, the prognosis of cancer patients and the effect of CIT. The main hematological parameters reported so far include absolute neutrophil count (ANC) (5), absolute lymphocyte count $(5,6)$, absolute eosinophil count (5), neutrophil-to-lymphocyte ratio (NLR) $(7,8)$, platelet-to-lymphocyte ratio (PLR) (8), derived NLR (dNLR, which is ANC divided by absolute white blood cell count minus ANC) (9), C-reactive protein (CRP) (10), CRP-to-albumin ratio (CAR) (11), and systemic immuneinflammation index (SII, which is the platelet count multiplied by NLR) (12).

NLR has been reported to predict prognosis in patients with solid tumors. We reported that, in 19 NSCLC patients treated with nivolumab, NLR changed over time and the change reflected disease conditions (13). Some previous studies found that pre-treatment NLR $<5$ was associated with longer survival in patients treated with nivolumab $(7,8)$. In 
addition, post-treatment NLR $<5$ at various time points was reported to be a prognostic marker of response (12-14), suggesting that NLR may be a promising biomarker. While these results were supported by a pooled analysis of 14 retrospective studies (15), there was still difficulty to distinguish between responders and non-responders to nivolumab (13).

Recently, other blood-based inflammatory parameters, such as red cell distribution width (RDW), have also been shown to be associated with survival in patients with solid tumors, including lung cancer (16). RDW is a hematological parameter routinely measured in complete blood count (CBC) analysis. Elevated RDW is related to erythropoiesis reaction in bleeding and hemolysis and is used in the differential diagnosis of anemia. RDW has been reported to be associated with adverse outcomes in a variety of respiratory diseases such as NSCLC (16), idiopathic pulmonary fibrosis (17), chronic obstructive pulmonary disease (18), and community-acquired pneumonia (19). The reference range for RDW in our hospital is 12.2$14.8 \%$. Although the cut-off value of $15 \%$ is widely used for RDW, it was reported that there was no significant difference in prognosis (according to OS) among stage III and IV NSCLC patients based on this cut-off value (16). It was reported that RDW increased as the stage progressed (16), suggesting that the optimal cut-off value is higher than $15 \%$. To our knowledge, the optimal cut-off value of RDW has not been reported and has not been studied in patients with stage III and IV NSCLC.

The prognostic values of the combination of NLR and RDW have been reported in epithelial ovarian cancer (20) and gastric cancer (21). We hypothesized that the combination of NLR and RDW could be useful for stratifying patient prognosis.

Our study reports, for the first time, that higher RDW is associated with poor outcomes in NSCLC patients who were previously treated with anti-PD-1 antibody and that the combination of NLR and RDW is useful for stratifying patient prognosis.

\section{Patients and Methods}

Patients and treatments. We performed a retrospective review of electronic medical and radiographic records and collected data on consecutive NSCLC patients (with stage III or IV or recurrent NSCLC) treated with either nivolumab or pembrolizumab from December 2015 to April 2018 at the Kobe University Hospital, Japan.

The data collected from the patients' medical and radiographic records included the following: gender, age, smoking history, Eastern Cooperative Oncology Group Performance Status (ECOG PS) at treatment initiation, targetable driver mutation status with respect to epidermal growth factor receptor $(E G F R)$, anaplastic lymphoma kinase $(A L K)$, and proto-oncogene tyrosine kinase $R O S 1$ (ROS1), PD-L1 expression status, prior therapy line (first, second, or third or more), and follow-up status (dead or alive).
Nivolumab or pembrolizumab was administered intravenously at doses of $3 \mathrm{mg} / \mathrm{kg}$ every 2 weeks and $200 \mathrm{mg} / \mathrm{kg}$ every 3 weeks, respectively. Tumor evaluations were performed every 2-3 cycles with computed tomography.

This retrospective analysis was approved by the Institutional Review Board of Kobe University Hospital (\#180169), and all patients signed a comprehensive written informed consent form. All data were fully anonymized before the analysis was carried out.

Laboratory analyses. Laboratory samples were collected prior to the patients starting treatment. CBC analyses were performed using the Sysmex XN-9000 hematology analyzer (Sysmex Co., Kobe, Japan). In accordance with the hospital's laboratory policy, CBC was performed within $1 \mathrm{~h}$ of sample collection. Analyses were performed at room temperature. Total white blood cell, neutrophil and lymphocyte counts, and RDW were determined by performing $\mathrm{CBC}$ analyses. NLR was defined as the absolute neutrophil count divided by the absolute lymphocyte count. The cutoff value for NLR was set at 5 , which is a commonly used threshold for NLR. We estimated the optimal cutoff value for NSCLC cancer (stage III or IV or recurrent NSCLC) to be $>15 \%$, which was determined based on the RDW distribution map.

Statistical analyses. OS was calculated from the date of treatment initiation to the date of the patient's death due to any cause. Patients who were still alive were censored at the last follow-up. Similarly, PFS was defined as the time from the date of treatment initiation to the date of first evidence of disease progression (as documented by imaging, according to Response Evaluation Criteria In Solid Tumors [RECIST] version 1.1 , or as indicated by clinical examination) or death. Patients who were still alive and did not have disease progression were censored at the last follow-up. Response to therapy was assessed by the treating physician and was classified as complete response (CR), partial response (PR), stable disease (SD), progressive disease (PD), or not evaluable (NE).

All statistical analyses were performed using EZR (Saitama Medical Center, Jichi Medical University, Saitama, Japan, version 1.35), which is a graphical user interface for $R$ ( $R$ Foundation for Statistical Computing, Vienna, Austria, version 3.3.2) (22). The Shapiro-Wilk normality test was used to test whether the continuous variables conformed to a normal distribution. Data that followed a normal distribution were expressed as the mean \pm standard deviation. For comparing data between two groups, Student's $t$-test was used to evaluate normally distributed data and the Mann-Whitney $U$-test was used to evaluate data that did not conform to a normal distribution. The Spearman test was used to assess the correlation between variables. The Kruskal-Wallis test was used to assess the differences among three or more groups. Survival curves were constructed using the Kaplan-Meier method and compared using the log-rank test. The Cox proportional hazard model was used to determine the significance of potential clinical factors on overall survival. All statistical tests were considered statistically significant at a $p$-value $<0.05$.

\section{Results}

Patient characteristics. Based on our previous study, we expanded the number of patients. The patients were previously treated NSCLC with an anti-PD-1 antibody (either nivolumab or pembrolizumab). We performed a retrospective review of 47 patients who started treatment from December 2015 to 


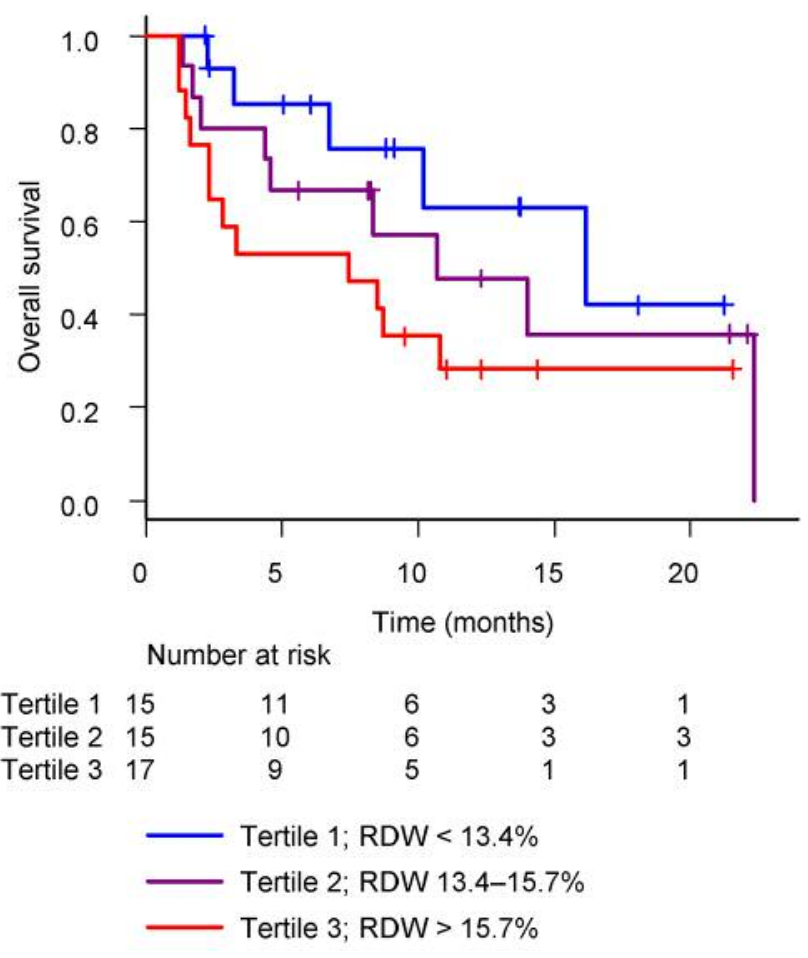

Figure 1. Overall survival by tertiles of red blood cell distribution width $(R D W)$. The median OS for patients with tertile 1, 2 and 3 was 16.2 (95\%CI=6.8-not reached), 10.7 (95\%CI=2.0-not reached), and 7.5 (95\%CI=1.6-not reached) months ( $p=0.152)$, respectively.

April 2018 at the Kobe University Hospital. Among them, 37 patients $(78.7 \%)$ were treated with nivolumab and 10 patients $(21.3 \%)$ were treated with pembrolizumab. The median age was 70 (range $=41-82$ years) years. The most common categories were male $(87.2 \%)$, smoker $(91.5 \%)$, good $(0-1)$ ECOG PS (89.4\%), and adenocarcinoma (57.4\%). Sixteen patients $(34.0 \%)$ had received one prior systemic therapy, 17 patients $(36.2 \%)$ had received two prior systemic therapies, and 14 patients $(29.8 \%)$ had received three or more prior systemic therapies. The median follow-up from treatment initiation was 8.4 months (range=1.2-22.7 months; interquartile range [IQR], 2.6-12.5). As of September 2018, 26 patients $(55.3 \%)$ died. The median OS and PFS was 10.7 (95\% confidence interval $[\mathrm{CI}]=6.8-$ not reached) and 3.9 (95\% CI=1.8-6.2) months, respectively.

Pre-treatment $R D W$. When dividing the population into three groups according to the tertiles of RDW, a higher RDW was associated with a trend towards shorter OS, as shown in Figure 1. The RDW value for each RDW quartile is shown in bar graphs (Figure 2). The slope is steep in the highest quartile, suggesting that elevated RDW in this group has been affected by some factors.

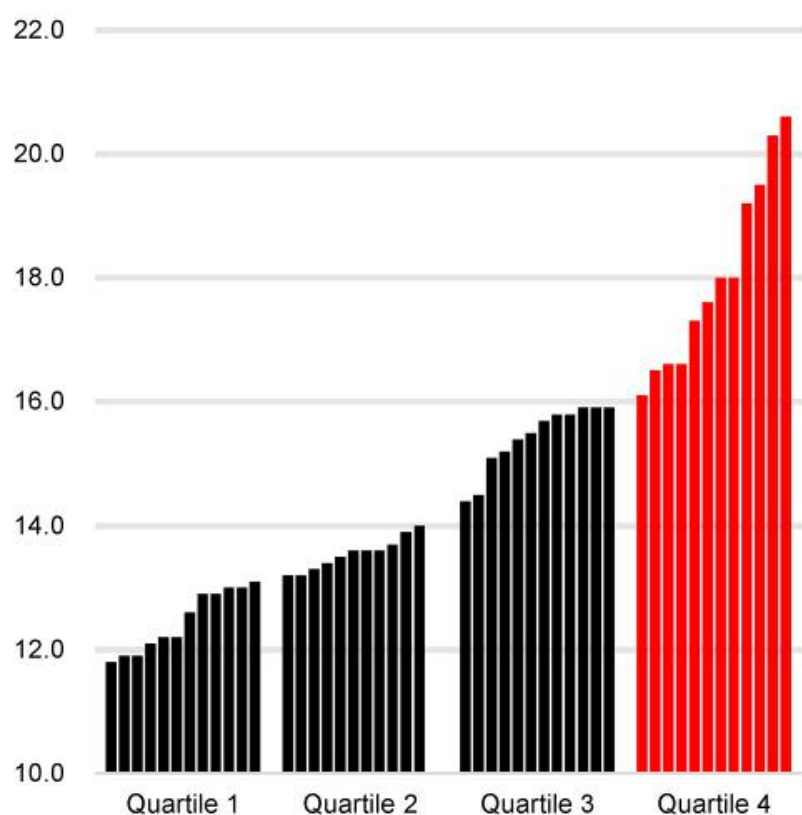

Figure 2. Bar graphs showing the red blood cell distribution width $(R D W)$ value for each quartile.

The median pre-treatment RDW was $14.4 \%$ (range $=11.8$ 20.6; IQR=13.2-16.0). Based on a cut-off value of $16 \%$, which represents the third quartile, patients were divided into two groups, comprising 12 patients $(25.5 \%)$ with RDW $\geq 16 \%$ and 35 patients $(74.5 \%)$ with RDW $<16 \%$. The clinical and laboratory characteristics of these groups are summarized in Table I.

The median OS for patients with RDW $\geq 16 \%$ and $<16 \%$ was $5.4(95 \% \mathrm{CI}=1.2-10.8)$ and $16.2 \quad(95 \% \mathrm{CI}=8.4-$ not reached) months $(p=0.010)$ (Figure $3 \mathrm{~A})$, respectively. The median PFS for patients with RDW $\geq 16 \%$ and $<16 \%$ was 2.1 (95\% CI=0.4-6.2) and 4.7 (95\% CI=1.9-6.8) months $(p=0.120)$ (Figure 3B), respectively. As with the NLR results, RDW $\geq 16 \%$ was significantly associated with a shorter OS $(p=0.010)$ compared with RDW $<16 \%$. This suggests a novel interpretation of pre-treatment RDW as a prognostic marker in NSCLC patients previously treated with anti-PD-1 antibody.

Independent prognostic value of pre-treatment NLR and $R D W$. Cox proportional hazard models, adjusted for covariates, were estimated. Multivariate analyses performed on relevant clinical factors (age, gender, ECOG PS, smoking status, NLR, and RDW) showed that NLR $\geq 5$ (hazard ratio $[\mathrm{HR}]=4.47,95 \% \mathrm{CI}=1.77-11.28, p=0.002)$ and $\mathrm{RDW} \geq 16 \%$ $(\mathrm{HR}=2.76,95 \% \mathrm{CI}=1.05-7.25, p=0.039)$ were independently associated with shorter OS (Table II). 
Table I. Patient characteristics and clinicopathological data based on $R D W$ categorization.

\begin{tabular}{|c|c|c|c|}
\hline Variable & $\begin{array}{c}\mathrm{RDW} \geq 16 \% \\
(\mathrm{~N}=12)\end{array}$ & $\begin{array}{c}\text { RDW }<16 \% \\
(\mathrm{~N}=35)\end{array}$ & $p$-Value \\
\hline \multicolumn{4}{|l|}{ Gender } \\
\hline Male & 10 & 31 & \multirow[t]{2}{*}{0.637} \\
\hline Female & 2 & 4 & \\
\hline \multicolumn{4}{|l|}{ Age, years } \\
\hline Median (range) & $67(41-82)$ & $72(50-81)$ & \multirow{3}{*}{0.703} \\
\hline$\geq 75$ & 2 & 9 & \\
\hline$<75$ & 10 & 26 & \\
\hline \multicolumn{4}{|l|}{ Smoking history } \\
\hline Heavy ( $\geq 20$ pack-year) & 9 & 30 & \multirow[t]{3}{*}{0.243} \\
\hline Light (<20 pack-year) & 2 & 1 & \\
\hline Never & 1 & 4 & \\
\hline \multicolumn{4}{|l|}{ ECOG PS } \\
\hline $0-1$ & 9 & 33 & \multirow[t]{2}{*}{0.097} \\
\hline $2-4$ & 3 & 2 & \\
\hline \multicolumn{4}{|l|}{ Histology } \\
\hline Adenocarcinoma & 6 & 21 & \multirow[t]{3}{*}{0.479} \\
\hline Squamous cell carcinoma & 3 & 8 & \\
\hline Other & 3 & 3 & \\
\hline \multicolumn{4}{|l|}{ Tumor stage } \\
\hline Stage III & 2 & 6 & \multirow[t]{3}{*}{0.680} \\
\hline Stage IV & 4 & 17 & \\
\hline Recurrent & 6 & 12 & \\
\hline \multicolumn{4}{|l|}{ Prior therapy line } \\
\hline First & 3 & 13 & \multirow[t]{3}{*}{0.643} \\
\hline Second & 4 & 13 & \\
\hline Third or more & 5 & 9 & \\
\hline \multicolumn{4}{|l|}{ Targetable driver mutations } \\
\hline EGFR & 0 & 5 & 0.315 \\
\hline ALK & 0 & 0 & 1 \\
\hline ROS1 & 0 & 0 & 1 \\
\hline \multicolumn{4}{|l|}{$\begin{array}{l}\text { Programmed cell death- } \\
\text { ligand-1 (PD-L1) tumor } \\
\text { proportion score (TPS) }\end{array}$} \\
\hline$\geq 50 \%$ & 1 & 4 & \multirow[t]{4}{*}{0.859} \\
\hline $1-49 \%$ & 2 & 10 & \\
\hline$<1 \%$ & 2 & 6 & \\
\hline Unknown & 7 & 15 & \\
\hline \multicolumn{4}{|l|}{ Response } \\
\hline Progressive disease & 5 & 13 & \multirow[t]{4}{*}{0.137} \\
\hline Stable disease & 4 & 16 & \\
\hline Partial response & 1 & 6 & \\
\hline Not evaluable & 2 & 0 & \\
\hline \multicolumn{4}{|l|}{$\begin{array}{l}\text { Neutrophil-to-lymphocyte } \\
\text { ratio (NLR) }\end{array}$} \\
\hline Median (IQR) & $3.9(3.5-5.5)$ & $3.2(2.1-5.2)$ & \multirow{3}{*}{0.731} \\
\hline$\geq 5$ & 4 & 10 & \\
\hline$<5$ & 8 & 25 & \\
\hline
\end{tabular}

NLR: Neutrophil-to-lymphocyte ratio; RDW: red blood cell distribution width; PS: Performance Status; EGFR: epidermal growth factor receptor; ALK: anaplastic lymphoma kinase; ROS1: protooncogene tyrosine kinase c-ROS1; IQR: interquartile range.

Correlation between pre-treatment NLR and RDW. In the Spearman's correlation analysis, there was no significant correlation between NLR and RDW ( $\mathrm{r}=0.25, p=0.094)$
Table II. Factors that correlated with overall survival in multivariate Cox regression analysis $(N=47,26$ death events).

\begin{tabular}{lcc}
\hline Factors & Hazard ratio $(95 \% \mathrm{CI})$ & $p$-Value \\
\hline NLR & & \\
$\quad$ Low $(<5)$ & 1 (reference) & \\
High $(\geq 5)$ & $4.20(1.69-10.44)$ & 0.002 \\
RDW & 1 (reference) & \\
$\quad$ Low $(<16 \%)$ & $3.04(1.02-7.65)$ & 0.019 \\
High $(\geq 16 \%)$ & 1 (reference) & \\
Smoking history & $4.19(0.28-63.01)$ & 0.301 \\
$\quad$ Never & 1 (reference) & \\
Ever & $0.42(0.13-1.30)$ & 0.132 \\
Age & 1 (reference) & \\
$\quad<75$-year-old & $4.06(0.51-32.34)$ & 0.186 \\
$\geq 75$-year-old & 1 (reference) & \\
Gender & $1.39(0.25-7.76)$ & 0.707 \\
$\quad$ Male & Female & \\
Performance status & $0-1$ &
\end{tabular}

CI: Confidence interval; NLR: neutrophil-to-lymphocyte ratio; RDW: red blood cell distribution width.

(Figure 4A). The overlap between patients with NLR $\geq 5$ and RDW $\geq 16 \%$ was small, as shown in Figure 4B. These results suggest that elevated NLR and RDW are due to different backgrounds.

Combination of pre-treatment NLR and RDW. The clinical value of the combination of NLR and RDW was investigated. Patients were divided into three groups based on their NLR and RDW values, namely, patients with NLR $<5$ and RDW $<16 \%$ defined as NLR/RDW score 0 (low risk group), patients with NLR $\geq 5$ or RDW $\geq 16 \%$ were defined as NLR/RDW score 1 (intermediate risk group), and patients with NLR $\geq 5$ and RDW $\geq 16 \%$ were defined as NLR/RDW score 2 (high risk group). There were 25 patients (53.2\%) with NLR/RDW score 0,18 patients $(38.3 \%)$ with NLR/RDW score 1 , and 4 patients $(8.5 \%)$ with NLR/RDW score 2 .

The median OS for patients with NLR/RDW score 0,1 , and 2 was 16.2 (95\% CI=10.2-not reached), $7.5(95 \% \mathrm{CI}=2.0-$ $10.8)$, and 1.9 (95\% CI=1.2-not reached) months $(p<0.001)$ (Figure 5A), respectively. The median PFS for patients with NLR/RDW score 0,1 , and 2 was $5.3(95 \% \mathrm{CI}=3.9-10.2), 1.7$ (95\% CI=1.1-6.2), and 1.5 (95\% CI=0.4-not reached) months $(p=0.033)$ (Figure 5B), respectively. Interestingly, patients with NLR/RDW score 0 had better prognoses than those with NLR/RDW score 1 or 2 .

As a life expectancy of at least 3 months is listed as one of the eligibility criteria in clinical trials, we examined whether life expectancy can be predicted using the combination of NLR and RDW. For patients with NLR/RDW score 0,1 , and 
A

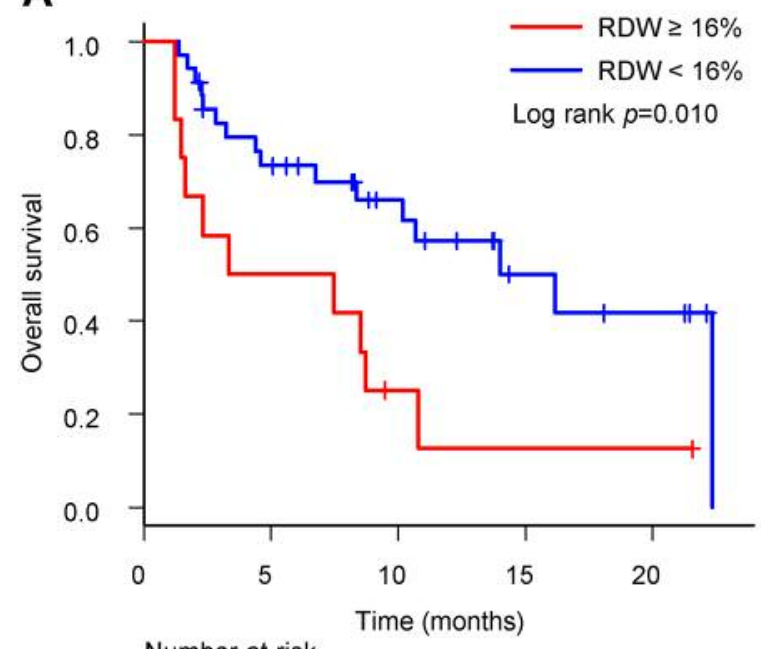

Number at risk
B

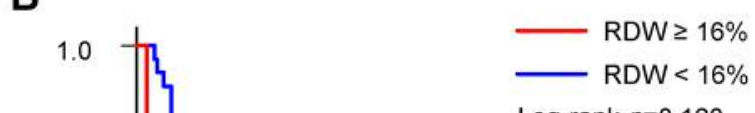

Log rank $p=0.120$

$\mathrm{RDW} \geq 16 \% 12$

$\mathrm{RDW}<16 \% 35$

$\begin{array}{cc}6 & 2 \\ 24 & 15\end{array}$

\begin{abstract}
2
\end{abstract}

\begin{abstract}
1
6
\end{abstract}
1

Figure 3. Overall survival and progression-free survival in patients with red blood cell distribution width (RDW) $\geq 16 \%$ versus $<16 \%$. (A) The median OS for patients with RDW $\geq 16 \%$ and $<16 \%$ was $5.4(95 \%$ CI=1.2-10.8) and $16.2(95 \%$ CI=8.4-not reached) months ( $p=0.010)$, respectively. (B) The median PFS for patients with RDW $\geq 16 \%$ and $<16 \%$ was 2.1 (95\%CI=0.4-6.2) and 4.7 (95\%CI=1.9-6.8) months (p=0.120), respectively.

A

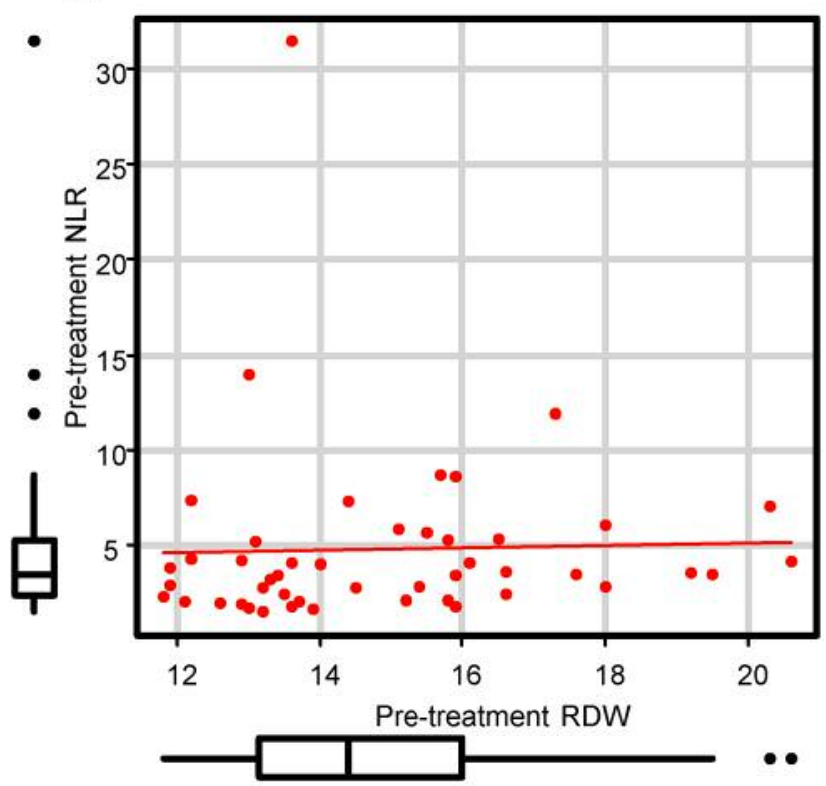

B

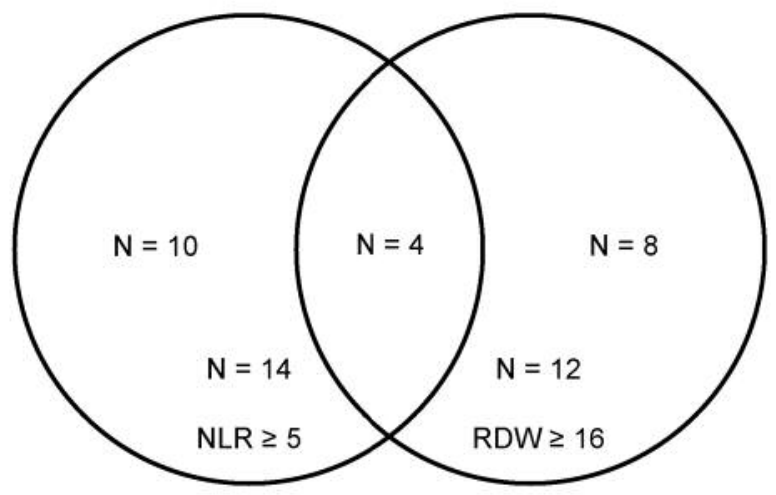

Figure 4. Correlation between pre-treatment neutrophil-to-lymphocyte ratio (NLR) and red blood cell distribution width (RDW). (A) Pearson correlation scatter plot of NLR and RDW ( $r=0.25, p=0.094)$. (B) Venn diagram showing numbers and overlapping of patients with NLR $\geq 5$ and/or RDW $\geq 16 \%$.

2, the mortality rate within 3 months was $4.2 \%(1 / 24), 38.9 \%$ (7/18), and $75.0 \%(3 / 4)$, respectively. We could clearly stratify NSCLC patients treated with an anti-PD-1 antibody into three prognostic groups.

\section{Discussion}

Our study showed that pre-treatment RDW $\geq 16 \%$ was significantly associated with shorter OS in previously treated 

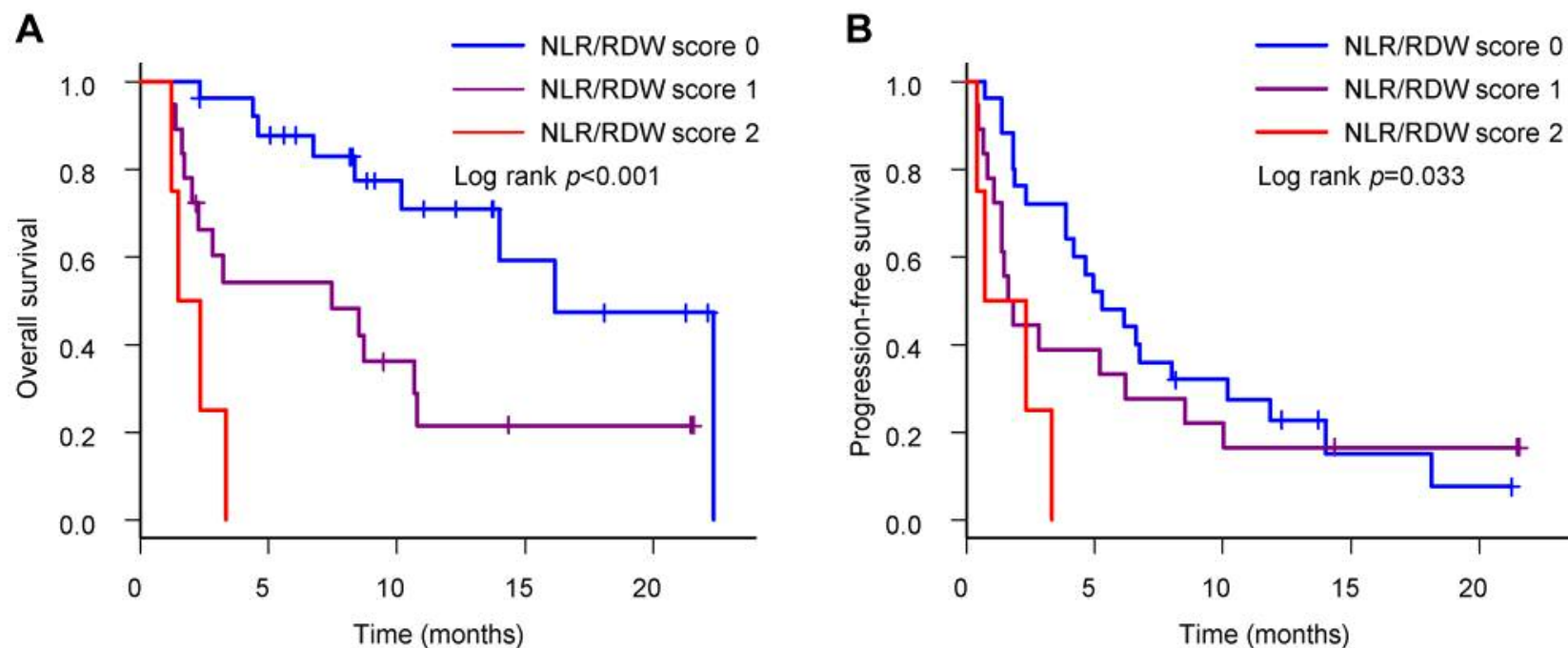

\begin{tabular}{cccccc}
\multicolumn{7}{c}{ Number at risk } \\
score 0 & 25 & 21 & 12 & 5 & 3 \\
score 1 & 18 & 9 & 5 & 2 & 2 \\
score 2 & 4 & 0 & 0 & 0 & 0
\end{tabular}

\begin{tabular}{cccccc}
\multicolumn{7}{c}{ Number at risk } \\
score 0 & 25 & 13 & 7 & 2 & 1 \\
score 1 & 18 & 7 & 4 & 2 & 2 \\
score 2 & 4 & 0 & 0 & 0 & 0
\end{tabular}

Figure 5. Overall survival and progression-free survival in patients stratified according to combination of neutrophil-to-lymphocyte ratio (NLR) and red blood cell distribution width (RDW). (A) The median OS for patients with NLR/RDW score 0, 1, and 2 was 16.2 (95\%CI=10.2-not reached), 7.5 (95\%CI=2.0-10.8), and 1.9 (95\%CI=1.2-not reached) months $(p<0.001)$, respectively. $(B)$ The median PFS for patients with NLR/RDW score 0,1 , and 2 was $5.3(95 \% C I=3.9-10.2), 1.7(95 \% C I=1.1-6.2)$, and $1.5(95 \% C I=0.4-$ not reached $)$ months $(p=0.033)$, respectively.

NSCLC patients treated with anti-PD-1 antibody. In addition, the combination of NLR and RDW was significantly associated with shorter PFS and OS. To the best of our knowledge, our study reports for the first time the clinical utility of RDW and the combination of NLR and RDW for patients with NSCLC (stages III or IV or recurrent NSCLC) treated with anti-PD-1 antibody.

PD-L1 expression (assessed using an immunohistochemistry assay with the murine 22C3 anti-human PD-L1 antibody) is widely used as a biomarker to predict treatment effects. Nevertheless, some patients with PD-L1 positivity do not improve after treatment with an anti-PD-1 antibody. Intratumoral heterogeneity has been reported (23), indicating a limit regarding the use of PD-L1 expression levels in biopsy specimens. Therefore, it is an important task for clinicians to identify a novel predictive marker to replace or to add to PDL1 in patients undergoing CIT.

In HIV-positive patients, it has been reported that elevated RDW indicates an increase in PD- 1 on $\mathrm{CD}^{+} \mathrm{T}$ cells, reflecting $\mathrm{CD}^{+} \mathrm{T}$ cell dysfunction (24). In metastatic NSCLC patients, it has been shown that high expression of $\mathrm{PD}-1$ on $\mathrm{CD}^{+}{ }^{+} \mathrm{T}$ cells in the peripheral blood results in an immunosuppressed state and an impaired antitumor response, leading to shorter PFS and OS (25). Additionally, when comparing NSCLC patients and healthy individuals, PD-1 on $\mathrm{CD}^{+} \mathrm{T}$ cells was significantly increased in NSCLC patients, suggesting that PD-1 on $\mathrm{CD}^{+}{ }^{+} \mathrm{T}$ cells plays an important role in immune tolerance (25). In our study, pre-treatment RDW was analyzed in NSCLC patients treated with an antiPD-1 antibody, and an elevated RDW was shown to be associated with poor prognosis in this population. These results suggest that elevated RDW may be a clinical prognostic marker in NSCLC patients treated with anti-PD1 antibody, reflecting increased expression of PD-1 on CD4 ${ }^{+}$ $\mathrm{T}$ cells.

There is no optimal cut-off value that defines elevated RDW in patients with metastatic NSCLC. Previous research on RDW in various types of cancers have used a variety of cut-off values $(16,26)$. In a prior study of 332 NSCLC patients (16), RDW was positively associated with clinical cancer stage. There was a significant difference in the prognosis (according to OS) among stage I and II NSCLC patients based on an RDW cutoff value of $15 \%$, while there was no significant difference in the prognosis among stage III and IV NSCLC patients. In contrast, in our cohort, there was a significant difference based on a cutoff value of $16 \%$. The optimal cut-off value for metastatic NSCLC should be further investigated.

A Cox proportional hazard model was used to evaluate the associations between OS and pre-treatment clinical factors (age, gender, ECOG PS, smoking status, NLR, and RDW). The final analysis revealed that NLR and RDW are 
independently related to OS. However, there was no significant correlation between NLR and RDW. Although the assumption that NLR is a promising biomarker of nivolumab response is now widely accepted, in the present study, we succeeded in stratifying patient prognosis (with regard to OS and PFS) by combining NLR and RDW. For patients with NLR $\geq 5$ and $R D W \geq 16 \%$, careful consideration may be required regarding the use of other therapeutic agents and the determination of the effects of early treatment.

Our study was a single-institution, retrospective, small study, with several limitations. All previously treated NSCLC patients treated with either nivolumab or pembrolizumab were included, which limited potential selection biases that can sometimes occur in this type of analysis. Response to therapy and PFS were assessed by the treating physician and classified using RECIST, but the timing of the evaluation depended on the physicians and drugs used. These diversities could have introduced bias into our study. Factors such as serum iron, ferritin, vitamin B12, and folic acid were not assessed, and respiratory comorbidities that may affect RDW, such as chronic obstructive pulmonary disease, idiopathic pulmonary fibrosis, and obstructive sleep apnea syndrome were not evaluated.

In summary, $\mathrm{RDW} \geq 16 \%$ is predictive of poor prognosis. NLR and RDW are inexpensive, convenient, and routinely available biomarkers. Given our results, mortality risk in NSCLC patients treated with anti-PD-1 antibody can be reclassified using the combination of NLR and RDW. Further studies are needed to validate the prognostic role of RDW in this setting.

\section{References}

1 Herbst R, Baas P, Kim D-W, Felip E, Pérez-Gracia J, Han J-Y, Molina J, Kim J-H, Arvis C, Ahn M-J, Majem M, Fidler M, de Castro G, Garrido M, Lubiniecki G, Shentu Y, Im E, DolledFilhart $\mathrm{M}$ and Garon E: Pembrolizumab versus docetaxel for previously treated, PD-L1-positive, advanced non-small-cell lung cancer (KEYNOTE-010): a randomised controlled trial. Lancet 387: 1540-1550, 2016.

2 Rittmeyer A, Barlesi F, Waterkamp D, Park K, Ciardiello F, von Pawel J, Gadgeel S, Hida T, Kowalski D, Dols M, Cortinovis D, Leach J, Polikoff J, Barrios C, Kabbinavar F, Frontera O, Marinis F, Turna H, Lee JS, Ballinger M, Kowanetz M, He P, Chen D, Sandler A, Gandara D and Group O: Atezolizumab versus docetaxel in patients with previously treated non-smallcell lung cancer $(\mathrm{OAK})$ : a phase 3, open-label, multicentre randomised controlled trial. Lancet 389: 255-265, 2017.

3 Borghaei H, Paz-Ares L, Horn L, Spigel D, Steins M, Ready N, Chow L, Vokes E, Felip E, Holgado E, Barlesi F, Kohlhäufl M, Arrieta O, Burgio M, Fayette J, Lena H, Poddubskaya E, Gerber D, Gettinger S, Rudin C, Rizvi N, Crinò L, Blumenschein G, Antonia $\mathrm{S}$, Dorange $\mathrm{C}$, Harbison $\mathrm{C}$, Finckenstein $\mathrm{F}$ and Brahmer J: Nivolumab versus docetaxel in advanced nonsquamous non-small-cell lung cancer. New Engl J Med 373: $1627-1639,2015$
4 Brahmer J, Reckamp K, Baas P, Crinò L, Eberhardt W, Poddubskaya E, Antonia S, Pluzanski A, Vokes E, Holgado E, Waterhouse D, Ready N, Gainor J, Frontera O, Havel L, Steins M, Garassino M, Aerts J, Domine M, Paz-Ares L, Reck M, Baudelet C, Harbison C, Lestini B and Spigel D: Nivolumab versus Docetaxel in Advanced Squamous-Cell Non-Small-Cell Lung Cancer. New Engl J Med 373: 123-135, 2015.

5 Tanizaki J, Haratani K, Hayashi H, Chiba Y, Nakamura Y, Yonesaka K, Kudo K, Kaneda H, Hasegawa Y, Tanaka K, Takeda M, Ito A and Nakagawa K: Peripheral blood biomarkers associated with clinical outcome in non-small cell lung cancer patients treated with nivolumab. J Thorac Oncol 13: 97-105, 2018.

6 Karantanos T, Karanika S, Seth B and Gignac G: The absolute lymphocyte count can predict the overall survival of patients with non-small cell lung cancer on nivolumab: a clinical study. Clin Transl Oncol, 2018. doi: 10.1007/s12094-018-1908-2. [Epub ahead of print]

7 Bagley SJ, Kothari S, Aggarwal C, Bauml JM, Alley EW, Evans TL, Kosteva JA, Ciunci CA, Gabriel PE, Thompson JC, Stonehouse-Lee S, Sherry VE, Gilbert E, Eaby-Sandy B, Mutale F, DiLullo G, Cohen RB, Vachani A and Langer CJ: Pretreatment neutrophil-to-lymphocyte ratio as a marker of outcomes in nivolumab-treated patients with advanced nonsmall-cell lung cancer. Lung Cancer 106: 1-7, 2017.

8 Diem S, Schmid S, Krapf M, Flatz L, Born D, Jochum W, Templeton AJ and Früh M: Neutrophil-to-Lymphocyte ratio (NLR) and Platelet-to-Lymphocyte ratio (PLR) as prognostic markers in patients with non-small cell lung cancer (NSCLC) treated with nivolumab. Lung Cancer 111: 176-181, 2017.

9 Russo A, Franchina T, Ricciardi GRRR, Battaglia A, Scimone A, Berenato R, Giordano A and Adamo V: Baseline neutrophilia, derived neutrophil-to-lymphocyte ratio (dNLR), platelet-tolymphocyte ratio (PLR), and outcome in non small cell lung cancer (NSCLC) treated with Nivolumab or Docetaxel. J Cell Physiol 233: 6337-6343, 2018.

10 Oya Y, Yoshida T, Kuroda H, Mikubo M, Kondo C, Shimizu J, Horio Y, Sakao Y, Hida T and Yatabe Y: Predictive clinical parameters for the response of nivolumab in pretreated advanced non-small-cell lung cancer. Oncotarget 5: 103117-103128, 2014.

11 Inoue T, Tamiya M, Tamiya A, Nakahama K, Taniguchi Y, Shiroyama T, Isa S-I, Nishino K, Kumagai T, Kunimasa K, Kimura M, Suzuki H, Hirashima T, Atagi S and Imamura F: Analysis of early death in japanese patients with advanced nonsmall-cell lung cancer treated with nivolumab. Clin Lung Cancer 19: e171-e176, 2018.

12 Suh KJ, Kim SH, Kim YJ, Kim M, Keam B, Kim TM, Kim DWW, Heo DS and Lee JS: Post-treatment neutrophil-tolymphocyte ratio at week 6 is prognostic in patients with advanced non-small cell lung cancers treated with anti-PD-1 antibody. Cancer Immunol Immunother 67: 459-470, 2018.

13 Kiriu T, Yamamoto M, Nagano T, Hazama D, Sekiya R, Katsurada M, Tamura D, Tachihara M, Kobayashi K and Nishimura Y: The time-series behavior of neutrophil-tolymphocyte ratio is useful as a predictive marker in non-small cell lung cancer. PLoS ONE 13: e0193018, 2018.

14 Takeda T, Takeuchi M, Saitoh M and Takeda S: Neutrophil-tolymphocyte ratio after four weeks of nivolumab administration as a predictive marker in patients with pretreated non-small-cell lung cancer. Thorac Cancer 9: 1291-1299, 2018. 
15 Cao D, Xu H, Xu X, Guo T and Ge W: A reliable and feasible way to predict the benefits of Nivolumab in patients with nonsmall cell lung cancer: a pooled analysis of 14 retrospective studies. Oncoimmunology 7: 1-9, 2018.

16 Koma Y, Onishi A, Matsuoka H, Oda N, Yokota N, Matsumoto Y, Koyama M, Okada N, Nakashima N, Masuya D, Yoshimatsu $\mathrm{H}$ and Suzuki Y: Increased red blood cell distribution width associates with cancer stage and prognosis in patients with lung cancer. PLoS ONE 8: e80240, 2013.

17 Nathan SD, Reffett T, Brown AW, Fischer CP, Shlobin OA Ahmad S, Weir N and Sheridan MJ: The red cell distribution width as a prognostic indicator in idiopathic pulmonary fibrosis. Chest 143: 1692-1698, 2013.

18 Seyhan EC, Özgül MA, Tutar N, Ömür I, Uysal A and Altin S: Red blood cell distribution and survival in patients with chronic obstructive pulmonary disease. COPD 10: 416-424, 2013.

19 Lee J, Chung H, Kim K, Jo Y, Rhee J, Kim Y and Kang K: Red cell distribution width as a prognostic marker in patients with community-acquired pneumonia. Am J Emerg Med 31: 72-79, 2013.

20 Li Z, Hong N, Robertson M, Wang C and Jiang G: Preoperative red cell distribution width and neutrophil-to-lymphocyte ratio predict survival in patients with epithelial ovarian cancer. Sci Rep 7: 43001, 2017.

21 Zhou D, Wu Y, Lin Z, Shi L, Zhao L, Liu T, Yu D and Zhang T: Prognostic value of combination of pretreatment red cell distribution width and neutrophil-to-lymphocyte ratio in patients with gastric cancer. Gastroent Res Pract 2018: 8042838, 2018.
22 Kanda Y: Investigation of the freely available easy-to-use software "EZR" for medical statistics. Bone Marrow Transplant 48: 452-458, 2013.

23 McLaughlin J, Han G, Schalper K, Carvajal-Hausdorf D, Pelakanou V, Rehman J, Velcheti V, Herbst R, LoRusso P and Rimm D: Quantitative assessment of the heterogeneity of PD-L1 expression in non-small-cell lung cancer. Jama Oncol 2: 1-9, 2015.

24 Al-Kindi S, Zidar D, McComsey G and Longenecker C: Association of anisocytosis with markers of immune activation and exhaustion in treated HIV. Pathog Immun 2: 138-150, 2017.

25 Zheng H, Liu X, Zhang J, Rice SJ, Wagman M, Kong Y, Zhu L, Zhu J, Joshi M and Belani CP: Expression of PD-1 on CD4 ${ }^{+} \mathrm{T}$ cells in peripheral blood associates with poor clinical outcome in non-small cell lung cancer. Oncotarget 7: 56233-56240, 2016.

26 Hu L, Li M, Ding Y, Pu L, Liu J, Xie J, Cabanero M, Li J, Xiang $\mathrm{R}$ and Xiong S: Prognostic value of RDW in cancers: a systematic review and meta-analysis. Oncotarget 8: 1602716035, 2017.

Received October 18, 2018

Revised October 30, 2018

Accepted October 31, 2018 